\title{
O GESTUS SOCIAL EM BRECHT: UMA ANÁLISE ACERCA DE HISTÓRIAS DO SR.KEUNER
}

\author{
THE SOCIAL GESTUS IN BRECHT: AN ANALYSIS OF \\ STORIES OF MR. KEUNER
}

\author{
Thaís Aparecida Domenes Tolentino \\ Universidade Federal de Santa Catarina, Florianópolis, Santa Catarina, Brasil \\ tolentinothais@gmail.com
}

Resumo: Este trabalho tem como objetivo, a partir da aproximação entre elementos estéticos e teóricos, debruçar-se sobre o conceito de gestus social na obra de Bertolt Brecht, com atenção especial voltada para a relação entre sua teoria do teatro épico e seus escritos em prosa concatenados em Histórias do sr. Keuner. Ao considerar a produção artística como um laboratório experimental de (des)montagem de pormenores significativos, as fronteiras entre formas de arte e formas de vida se diluem numa reinvenção da técnica de linguagem. Além disso, ao tomar a história como montagem, no caminho contrário ao historicismo clássico, ele desestabiliza paradigmas epistemológicos da história da arte para pensar a arte construída a partir da sobrevivência de imagens - gestus.

Pallavras-chave: Bertolt Brecht; gestus; Histórias do Sr. Keuner

Abstract: This work aims to approach the concept of social gestus in Bertolt Brecht's work, with a special focus on the relationship between his theory of the epic theater and his concatenated prose writings in Stories of Mr. Keuner. In considering artistic production as an experimental laboratory of (dis)assembling significant details, the boundaries between art forms and life forms are diluted in a reinvention of the language technique. In addition, by taking history as a montage, on the road contrary to classical historicism, it destabilizes epistemological paradigms of art history to think of art constructed from the survival of images - gestus.

Keywords: Bertolt Brecht; gestus; Stories of Mr. Keuner

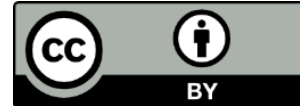




\section{Introdução}

Pensar a atualidade da obra de Bertolt Brecht bem como de sua teoria da arte requer um olhar, um ponto de vista, ou como o coloca Georges Didi-Huberman (2017) em Quando as imagens tomam posição - $O$ olho da história I, uma tomada de posição, que ultrapasse a linearidade crônica do historicismo e seus pressupostos - e preconceitos - teóricos para entendê-la como história da sobrevivência de imagens, de ruínas. Pois que a contemporaneidade, em tempos de sobreposição de fluxos e refluxos de imagens que não cessam de constituir-se em novas configurações de formas e pensamentos, parece não mais sustentar uma teoria da modernidade que não se oponha à estética do "dever ser", de uma exigência categórica dos conceitos. Frente ao estado de complexização da verdade, em que o factual e visível constituem-se como espécie de montagem, a arte choca-se com a memória, para abrir espaço ao entre-lugar da obra. À essa primeira tomada de posição, colocam-se questões fundamentais para sustentar a análise aqui pretendida acerca do gestus social brechtiano enquanto categoria estrutural de sua obra teórica e literária: sua condição/posição de exilado e seu método experimental de des-montagem, de tonar visível os anacronismos e as sobrevivências. A proximidade de tais elementos, que servem a Didi-Huberman na medida em que analisa o Diário de Trabalho e o ABC da Guerra, escritos por Brecht entre 1933 e 1955, parecem tornar fértil o terreno para pensar - desmontar e reaproximar - a inclassificável prosa do autor, produzida e publicada ao longo de trinta anos, reunida na obra Histórias do sr. Keuner.

\section{Arqueologia do gesto: uma questão de método}

Falar de Bertolt Brecht (1898 - 1956) requer algumas notas biográficas, não no sentido de que elas justifiquem sua produção, mas porque aqui o "tempo sombrio" parece penetrar de forma profunda vida e obra, tornando fértil o terreno de investigação sobre a complexa relação entre arte e modernidade. De sua geração, fizeram parte homens e mulheres que, na primeira metade do século XX, vivenciaram a emergência do totalitarismo, seja sob a forma do nazismo, seja sob a do fascismo ou do stalinismo; que carregam as distintas marcas do exílio em sua história - aqui não mais possível de ser apreendida como a História.

Hannah Arendt (1906 - 1975), no conjunto de ensaios biográficos Homens em tempos sombrios, escrito ao longo de um período de doze anos, além de compartilhar a vida afetada pelo tempo histórico com as pessoas sobre as quais dedica seu registro, empresta do poema $\grave{A}$ posteridade, de Brecht, o termo-chave para sua coletânea de biografias inseridas na desordem, na fome, nos massacres, "[...] quando havia só injustiça e nenhuma indignação [...]” (BRECHT apud ARENDT, 2008, p. 243), homens de "tempos sombrios". A aproximação entre ambos não é fortuita. Para a filósofa, cuja relação com o dramaturgo alemão se intensifica a partir do contato com Walter Benjamin (1892 - 1940), falar de Brecht é caso de relação incerta entre poesia e política, capítulo inescapável de qualquer tentativa de apreensão do desenvolvimento das vanguardas da arte moderna, com a qual Brecht estabelece uma relação complexa.

Se, de partida, algumas pinceladas acerca da biografia do autor colocam-se como necessárias, a intenção não é a de constituir um todo coerente, mas dirige-se, antes, no sentido de não perder de vista o fato específico que se cristaliza em sua produção artística e teórica: a condição de poeta exilado, tanto de um lado quanto do outro da cortina de ferro que seria erigida nos anos subsequentes à ascensão fascista na Alemanha, condição que parece condensar-se numa configuração específica de discurso. Escamotear o contexto no qual Brecht parece esteve 
inserido pode incorrer no perigo da esterilização da sua teoria. Interessa-me mais de perto, a partir do ensaio de Arendt, perceber não a relação entre o conteúdo político em si que perpassa os escritos de Brecht, tampouco sua atuação militante, mas destacar um elemento que salta aos olhos ao longo de sua produção - o gesto adotado pelo autor.

Em Diário de Trabalho e ABC da Guerra, Brecht constrói um verdadeiro atlas de imagens que, segundo Didi-Huberman no primeiro volume de $O$ olho da História, trata-se de um conhecimento pela montagem: através do distanciamento, ele parece liquidar as fronteiras da obra de arte fechada. Enquanto o primeiro transita no terreno entre diário de pensamento e lírica de guerra, o segundo diz respeito à união entre imagens de crimes e textos de poesia que subvertem o sentido pedagógico clássico das cartilhas de alfabetização, ou os $A B C s . .$. - são obras em que o aspecto da montagem parece sobressair ao conteúdo da enunciação. A história é remontada a partir de uma tomada de posição que se constituirá elemento central de toda sua obra. Tomar posição é distanciar-se sem excluir a empatia, mas suspendê-la - esse é o gestus adotado pelo autor.

E o distanciar-se, para Brecht, não está desligado de sua posição de "exilado", ou seja, a posição de "homem em tempo sombrio" conforme Hannah Arendt. A posição de exilado parece materializar-se na sua forma de disposição (observar a estranheza) e dis-posição (desmontar a ordem) das coisas, elementos indissociáveis e em constante relação de tensão, para remontar a história através da interposição de campos estéticos.

\footnotetext{
O caso de Bertolt Brecht surge sob esse aspecto, como exemplar: seu exílio começa em 28 de fevereiro de 1933, imediatamente após o incêndio do Reichstag. A partir desse momento, ele erra de Praga a Paris e de Londres a Moscou; estabelece-se em Svendborg, na Dinamarca; passa por Estocolmo; atinge a Finlândia; reparte para Leningrado, moscou e Vladivostok; fixa-se em Los Angeles; detém-se em Nova York; deixa os Estados Unidos no dia seguinte ao seu depoimento diante da Comissão de Inquérito sobre as Atividades Antiamericanas; chega a Zurique antes de encontrar-se definitivamente em Berlim. Ele não voltará à Alemanha antes de 1948; terá, então, passado 15 anos de sua vida "sem teatro, muitas vezes sem dinheiro, vivendo em países cuja língua não era a sua", entre o acolhimento e a hostilidade, sobretudo a dos processos macarthistas que teve de enfrentar na América (DIDI-HUBERMAN, 2017, p. 16-17, tradução de Cleonice Paes Barreto Mourão).
}

A interposição de campos estéticos salta aos olhos quando se pensa a prosa brechtiana reunida em Histórias do sr. Keuner. Em que medida o processo de montagem e desmontagem estrutura, à exemplo do $A B C$ de Guerra e do Diário de Trabalho, parece ser latente para se pensar a modernidade da obra de arte e as possibilidades da atualidade de Brecht. A experiência dadaísta com a montagem, especialmente após a carnificina da Primeira Guerra Mundial, é refratada em suas experiências artísticas, pensando-as como recomposição da atualidade.

Diário de Trabalho constitui-se como uma espécie de ateliê provisoriamente em desordem. Ele renuncia ao valor dedutivo da exposição da guerra para desenvolver mais livremente o valor mostrativo - um diário de pensamento como sala de montagem, reunindo recortes de textos e imagens que rompem as barreiras entre o privado e a história, a literatura e o documento. Ele alcança a arte da fotomontagem adotando uma tomada de posição, "Mas não via nada sem desconstruir e depois remontar, por conta própria, a fim de melhor expô-la, a matéria visual que havia escolhido examinar" (DIDI-HUBERMAN, 2017, p. 30). A imagem torna-se superfície privilegiada para os complexos processos memoriais. Em $A B C$ da Guerra, o poeta parece interrogar, subvertendo esse livro primordial que é a cartilha, a capacidade de saber ver, na atualidade, os documentos sombrios da história - são imagens dialeticamente 
suspensas, em que o estranhamento se constrói através da superposição de imagens de crimes à textos líricos que retomam a forma epigramática, numa anamnese estilística que poderia ser vista como fotoepigramática. É clara a manipulação contrastante do material histórico, tornando visíveis as polaridades cuja lição política pode ser deduzida pela organização espacial da montagem: há lamento, mas há frieza, ironia, humor; há distanciamento sem excluir o caráter empático inerente ao horror, ao espanto; há uma tomada de posição por excelência; um gestus.

A crítica de Brecht à identificação reflete-se numa arte da observação em que o objetivo do distanciamento é extrair dos processos representados o seu gestus social, ou seja, criar intervalos onde só se via unidade. A montagem leva a novos agrupamentos entre ordens de realidade e desarticula a percepção habitual das relações, abrindo e rompendo a regra estabelecida para o poder crítico da exceção, leva ao conhecimento através da estranheza.

Distanciar é demonstrar desmontando as relações de coisas mostradas juntas e agrupadas segundo suas diferenças. Não há distanciamento sem trabalho de montagem, que é a dialética da desmontagem e da remontagem, da decomposição e da recomposição de toda coisa. Mas, ao mesmo tempo, esse conhecimento pela montagem será também conhecimento por estranheza. Brecht o assume, exigindo abertamente que o exercício da razão crítica não seja ofuscado, mas ao contrário, incitado, reiniciado por tal "estranhamento" das coisas (DIDI-HUBERMAN, 2017, p. 65-66).

Para Brecht, dis-por é uma maneira de compreender as coisas em dialética na sua concretude, característica marcante da arte moderna que aprimora seus procedimentos formais a partir da experiência da guerra e do desenvolvimento da técnica fotográfica e cinematográfica. $\mathrm{Na}$ des-montagem há a confrontação de diferentes pontos de vista, permitindo ver o que atravessa sintomaticamente os discursos e suas contradições - é salutar debruçar-se sobre seus escritos teóricos concomitantemente à análise de sua práxis.

Grande parte de seus escritos teóricos foram publicados em Estudos sobre teatro - Bolle (1976) chama atenção para o ensaio Sobre poesia sem rimas com ritmos irregulares, de 1939, ano em que ele se muda para a Suécia, planeja seu exílio nos EUA e publica Mãe Coragem e seus filhos, como importante orientação de Brecht sobre essa nova técnica de linguagem. $\mathrm{O}$ condicionamento da produção artística e literária pelas forças dominantes é uma das marcas da literatura alemã de exílio - grande parte de sua teoria foi desenvolvida nos anos que esteve fora da Alemanha, especialmente entre 1933 e 1945. Ao posicionar-se no caminho contrário à arte tradicional, ilusionista, que nas mãos do fascismo resultou na estetização da política, Brecht opõe uma arte atenta às contradições sociais e suas relações com a estética, ou seja, uma teoria da arte fundada na politização da estética. Os "tempos sombrios" exigiam que a linguagem fosse pensada na sua função pública, não bastando exigir que a obra de arte fale de alguma coisa; o caráter de rompimento da arte moderna encontra-se mais próxima do como.

Se, por um lado, sua estética se coloca contra a realidade histórica do fascismo nacional socialista, tampouco ela se alinha às fileiras do realismo socialista, a exemplo de Lukács, embora suas análises se aproximem em determinados pontos, especialmente no que diz respeito às inter-relações entre formas de vida e formas de arte - Brecht compreende o teatro como uma das artes mais humanas, mais frequentemente praticadas, seja na cotidianidade, seja numa apresentação no palco, na tela, em que o apresentado é sempre uma sugestão de valores. As forças históricas dominantes seriam também de ordem estética, em que pelo menos dois elementos se destacam na sua análise sobre os discursos e a propaganda nazista: a da 
representação e a dramatização do discurso pautada numa relação de empatia de alto teor emotivo.

\footnotetext{
A pompa dos fascistas, considerada simplesmente como pompa, tem um gestus vazio, o gestus da pompa em si, um fenômeno sem qualidade; ao invés de pessoas andando, há pessoas marchando, alguma rigidez, muito colorido, peitos cheios de autoconfiança ostensiva, etc.; tudo isso poderia ser ainda o gestus de um divertimento para o povo, algo inócuo, algo puramente factual. Mas, no momento em que eles pisam em cima de cadáveres, surge o gestus social do fascismo (BRECHT, 1978, p. 195).
}

Daí que sua resposta teórica à esteticização da política, em que uma ideologia se apresenta como estética, seria a politização da estética, sob a qual se fundamenta seu teatro épico, que procura desmascarar tais encenações de uma estética política anestesiante através da análise crítica do gestus ideológico dominante. O conhecimento histórico torna-se, assim, uma verdadeira montagem temporal: a história tirada de seu lugar habitual tal qual aparece nas teses benjaminianas, com a condição de que o caráter anacrônico não se reduza a um amor aos escombros.

Retomando e retornando à ideia de gesto adotado por Brecht, e insistindo na hipótese de que ele transpassa seus escritos para tornar-se elemento estruturante de sua obra, não dissociado da complexidade de sua posição política e marcada pela história de seu tempo, dentro da qual se encontra a figura do poeta exilado, é salutar a reflexão sobre o entre-lugar ocupado pela sua obra num momento em que o surgimento das vanguardas artísticas ressignificaram o conceito de engajamento. Pois que Brecht, poeta de tempos sombrios, compartilha com o século XX uma radicalização da autocrítica da arte que na pintura, nas artes plásticas, na música, no cinema, na fotografia, dentre outras formas, se concretiza em termos de rompimento profundo com limites de uma arte e de uma hermenêutica tradicional.

Uma via para tornar mais palpável a ideia de pose, gestus, ou tomada de posição, adotada por Brecht pode ser pensada a partir da construção de Histórias do sr. Keuner. As 102 histórias que compõe a obra, postumamente reunidas no formato de um único volume, foram escritas ao longo de sua vida como uma espécie de diário de trabalho, recorrentemente compreendidas pela crítica a partir de um viés autobiográfico, sendo que muitas foram publicadas de forma esparsa e inseridas nas suas peças. Ou seja, são narrativas interpeladas a outros trabalhos estéticos e teóricos, mas que dialogam entre si, visto o constante trabalho crítico do autor de colocar em suspensão os modelos ideológicos da arte burguesa e, consequentemente, seus pressupostos ideológicos. As reminiscências da história, sem distinção das grandes e pequenas, são subvertidas por esse narrador, lidas a contrapelo, para que a partir delas seja possível analisar dialeticamente os homens em relação - que é também uma relação com toda a história.

\section{Histórias do sr. Keuner: quando as imagens tomam posição}

A aproximação entre o romance e o teatro não é fortuita para pensar aqui a dimensão em que se insere a prosa de Bertolt Brecht, reunida em Histórias do sr. Keuner. As 102 histórias, como antecipamos, são narrativas interpeladas a outros trabalhos estéticos e teóricos, que dialogam entre si, visto o constante trabalho crítico do autor de colocar em suspensão os modelos ideológicos da arte burguesa. Retomando o esforço à que, por ora, me dedico, o de pensar o gestus social de Brecht enquanto categoria estruturante de montagem, próxima de um caráter ensaístico, o faço tomando a prosa de Brecht em seu conjunto e vista como uma reação 
à tradição de um modelo de narrativa burguesa, resquício do Iluminismo que preponderava hegemonicamente até então. Se por um lado a considero literatura, visto seus elementos estéticos formais específicos, do qual sobressai o dialético narrador Keuner, por outro, também a aproximo do ensaio, uma vez que, ao questionar filosofica e politicamente os pressupostos da tradição, não se pode negar-lhe também o fato de ser teoria transmutada em experiência.

Muitas dessas considerações têm como ponto de partida o ensaio A verdade, minha vida e meu carro, de Vilma Botrel Coutinho de Melo, que acompanha a edição em língua portuguesa de Histórias do sr. Keuner, lançado em 2013 pela editora 34 e que contém quinze novos textos recém-descobertos. Além disso, a constante censura que Brecht enfrentou ao longo de sua vida reflete-se também, em certa medida, no fragmentarismo de sua obra.

Esse entre-lugar em que se encontra a prosa de Brecht, tal qual $A B C$ de Guerra e Diário de Trabalho, embora não determinado, não é desprovido de uma lógica de organização própria, no entanto, ela rompe e subverte a ordem epistemológica idealista e positivista. Ela é ficção amarrada/narrada por essa personagem Keuner, ao passo que é também teoria, na medida em que nelas encontramos os fundamentos do teatro épico bem como os princípios de seu pensamento ético e político-filosóficos.

Embora o autor nunca tenha feito menção ao significado do nome da personagem, ele “[...] pode ser entendido por duas vias: pelo termo grego koinós, 'o que diz respeito a todos' que se figura como ninguém em particular -, ou pela palavra keiner, 'ninguém', que se pronuncia 'koiner' no dialeto suábio alemão" (MELO, 2006, p. 125-135). Ele aparece pela primeira vez na peça-fragmento Decadência do egoísta Johan Fatzer, escrita em 1926, como um dos quatro famintos soldados convencidos por Fatzer a abandonar a guerra. Keuner é aquele que tem a sensibilidade maior para levar seus companheiros a refletir sobre si mesmos e a refletir sobre a possibilidade da bondade diante da barbárie, da necessidade de sobreviver na guerra, ele é o pensador distanciado - "KEUNER - Quanto mais se olhar, tanto menos / Um homem se parece com um homem (...)" (BRECHT, 1995, p. 214, tradução de Paulo César de Souza). Posteriormente Keuner passa a ser apresentado com a epígrafe 'aquele que pensa'. Para Brecht, na história intitulada Organização, "Aquele que pensa não usa nenhuma luz a mais, nenhum pedaço de pão a mais, nenhum pensamento a mais" (BRECHT, 1995, p. 12). Não é preciso grande esforço para aproximar "aquele que pensa" do historiador materialista de Benjamin - e, por quê não?, do ensaísta. Parece que não importa aqui saber sobre "sua pessoa", mas sim a postura que assume.

O interesse de Keuner não está, pois, na representação do ‘sujeito', mas sim na relação entre os sujeitos - que é, no fundo, um dos temas recorrentes na obra de Brecht. Novamente as narrativas de Brecht se aproximam do teatro: grande parte de suas histórias compuseram suas peças didáticas que, para além de um possível "ensinamento do marxismo", ligavam-se muito mais a um trabalho experimental de montagem teatral a partir do reconhecimento das contradições da realidade concreta. Se a realidade concreta não poderia ser abarcada pelas formas tradicionais de expressão, seja a arte ou a filosofia, o teatro também requeria novas funções.

Ao se colocar na função épica de comentador das ações, nas peças didáticas de Brecht, a personagem Keuner cumpre a função de desnudar as contradições, sejam elas do ponto de vista histórico, político, social ou estético. As contradições surgem das relações e, ao comentálas, Keuner as suspende para serem apresentadas dialeticamente, no momento em que relampejam. Ele interrompe a cena e torna a história um gesto citável. Brecht precisava de um 'pensador' que fizesse os comentários das parábolas entre os textos, como aparece na Peça 
didática de Baden-Baden sobre o acordo e como estava previsto para o Fatzer. "O pensador ficaria assentado numa cadeira e teria uma postura inquisidora e sábia” (MELO, 2006, p. 159).

Porém, Keuner é um sábio consciente da impossibilidade de uma verdade totalizante: talvez possamos pensá-lo como o ensaísta cuja argumentação não conduz a nenhuma verdade que não seja ela, também, dialética. "“"Quando estou em harmonia com as coisas”, disse o sr. Keuner, "eu não compreendo as coisas, elas me compreendem"” (BRECHT, 2013, p. 107). Esse micro-conto de poucas linhas parece sintetizar de forma potente que não há uma conclusão fechada para a argumentação de Keuner - trata-se de desnudar e deixar a história em aberto para ser pensada a partir de suas próprias contradições. Vista em seu conjunto, em que prevalece a ordenação dos elementos, não há uma conclusão senão um intenso processo dialético em que cada história é uma condensação extrema de ficção e teoria.

Assim como o ensaísta, Keuner é radical no não-radicalismo - penso por exemplo na história $O$ que é sábio no sábio é a postura, em que ele rechaça a postura do filósofo justamente por uma questão de gesto - "Você fala obscuramente, e nada esclarece ao falar. Vendo sua postura, não me interessa o seu objetivo" (BRECHT, 2013, p. 11), ou sintetizada no aforisma "Pensar significa transformar" (BRECHT, 2013, p. 70). Em Conhecimento dos homens, para além do ficcional, vemos a crítica ao tradicionalismo dos modelos de expressão, do papel do filósofo. Keuner é a retomada crítica do écrivan que fora excluído do âmbito acadêmico pelos defensores da ideia de uma verdade como totalidade, que só toleram como filosofia aquilo que é signo do universal. Outro aspecto importante que colabora para que a compreensão do surgimento das Histórias... é o combate que Brecht faz ao conceito wagneriano de obra de arte total, apontando para a separação dos elementos na composição de uma nova ópera, capaz de resultar numa atitude objetiva e distanciada do espectador. Para Benjamin (2017), o teatro épico de Brecht refletia essa nova postura que a realidade impunha ao artista de transformar o palco em tribuna, de liquidar a ideia de um teatro controlado pela literatura.

Para Brecht, somente o distanciamento permitiria uma atitude crítica do espectador frente à realidade. E é precisamente esse distanciamento uma marca característica da postura adotada pela personagem Keuner, capaz de tornar estranho aquilo que, pelo hábito, tornou-se natural. Keuner não age, ele é o que pensa diante da observação distanciada das ações, a partir das relações entre os homens. Há sempre um discípulo, um aluno, um filósofo, um menino etc., que o procura para indagar-lhe sobre as questões que excedem qualquer mediação unicamente literária, são homens que lhes pergunta sobre a vida. E suas respostas vêm sempre da história retomada criticamente, despida de qualquer " $h$ " maiúsculo.

\footnotetext{
Sobre a verdade

O discípulo Tief foi ao sr. Keuner, o que pensa, e disse: "Quero conhecer a verdade". "Que verdade? A verdade é conhecida. Você quer saber a verdade sobre o comércio pesqueiro? Ou sobre os impostos? Se, ao lhe dizerem a verdade sobre o comércio pesqueiro, você deixar de pagar tanto pelos peixes, você nunca saberá a verdade", disse o sr. Keuner." (BRECHT, 2013, p. 13).
}

Keuner encarnaria a figura do homem como processo, "para quem pensar não constitui uma atividade filosófica passiva, mas está profundamente ligado a uma "operação", de base dialética, que se destina a intervir nas relações entre o indivíduo e a coletividade" (MELO, 2006, p. 133), para quem a conceitualidade não passa de vivência.

Ressalta na obra também a organização fragmentária desse seu vasto trabalho, em que o parcial se acentua diante do total. Não há uma organização linear das histórias de forma que o leitor fica desobrigado de uma leitura encadeada e sequencial - seus fragmentos carregam a 
potência teórica e artística ainda que lidos independentemente. Ademais, Brecht não considerava seus trabalhos como obras prontas e acabadas, interessando-lhe antes o processo é possível pensar inclusive o anacronismo como elemento estruturante de sua obra, considerando as inúmeras intersecções existentes entre seus poemas, dramaturgia, ensaios, prosa, etc., constantemente retomados ao longo de sua produção.

$\mathrm{Na}$ esteira da mudança do pensamento filosófico e epistemológico do século XX, cuja relação com a crise do sistema capitalista burguês de produção é estreita, a obra de arte não passa imune. Se por um lado o ensaio - ou diário de pensamento, retomando Didi-Huberman ganha força como gênero de expressão do pensamento moderno que se coloca na contramão de uma filosofia tradicionalista pautada nos modelos totalizantes de verdade, ao se aproximar da obra de arte parece-me que colocou em xeque também a sua forma, sendo possível falar em cinema-ensaio, ensaio literário, foto ensaio, fotoepigrama, etc. A arte moderna e toda crítica à rigidez dos modelos burgueses idealistas desnudou também uma história em crise, uma crise da experiência materializada numa crise da narração típica das formas e modelos pautados numa lógica cartesiana que já não dava conta de explicar as contradições que se colocavam na ordem do dia. A prosa brechtiana faz parte desse conjunto de abalos que a arte e o pensamento moderno sofreram na medida em que ruía a hegemonia dos modelos tradicionalistas. Reconstruir Histórias do sr. Keuner é muito menos juntar peças de um quebra-cabeças ou ordenar fatos a partir de uma lógica historicista, do que compreender a dialética do pensamento em processo de Bertolt Brecht.

\section{Considerações finais}

Mostrar o mundo como ele aparece e como ele se deforma - eis gestus fundamental para se aproximar da produção artística e teórica de Bertolt Brecht. No caminho contrário à tomada de partido, da qual seria necessário pensar, por exemplo, a relação do dramaturgo alemão com o Partido Comunista soviético, Didi-Huberman mobiliza o olhar para a tomada de posição que salta aos olhos nas escolhas estéticas e teóricas da intrigante obra brechtiana. No seu ato de des-montagem, as emoções tornam-se históricas, atravessadas por uma memória que a aproxima de um lirismo fotográfico, imbuído da coragem de designar, de não deixar mudo o inaudito da história. Se do século XX, não imunes aos efeitos das catástrofes de duas guerras mundiais, pode-se falar em artistas empenhados numa arte da memória, Didi-Huberman toca na materialidade da produção de Brecht para esmiuçar o seu caráter épico, capaz de trazer à luz o latente. O tempo, esse passado-presente memorável, é, no teatro épico, um épos, em oposição ao lógos; ele é memória em ato, reunião da origem - arché - e não determinação da causa. $\mathrm{O}$ palco, a poesia, a teoria, a prosa são, para Brecht, um laboratório experimental de (des)montagem de pormenores significativos, de gestus sociais, de momentos citáveis, segundo Benjamin, em que as fronteiras entre formas de arte e formas de vida se diluem numa reinvenção da técnica de linguagem.

É fértil pontuar também outros elementos possíveis para se pensar as razões do teatro épico, que não estão desligadas da necessidade de apresentar as determinantes sociais das relações inter-humanas e ao intuito didático, construindo uma arte - e um método - capaz de esclarecer o público sobre a realidade social e a suas contradições. O teatro épico desenvolvido por Brecht surge, entre outras coisas, como expressão dos movimentos revolucionários pelos quais a Alemanha passou entre 1918 a 1923, período dentro da República de Weimar (19181933). Ao colocar entre seus temas a luta de classes, transformou as formas de produção teatral, 
subvertendo os mecanismos tradicionais da burguesia e agindo no sentido contrário ao abastecimento do aparelho produtivo pela indústria cultural. Ou seja, teatro épico não era apenas uma questão estética, mas apontava também para uma práxis social.

Se pensarmos a obra de arte como uma espécie de sismógrafo das estruturas sociais , cabe-nos (nós pesquisadores, teóricos críticos, professores, estudantes, etc.) estarmos atentos ao debate sobre o papel social da arte e do teatro nessa nova conjuntura política, econômica e social que se abre, sem perdermos de vista tanto o papel social de nossa própria função bem como contribuirmos com a retomada crítica do papel progressista - no sentido discutido por Benjamin (1994), em artigos como O Narrador e A obra de arte na Era de sua reprodutibilidade técnica - da obra de arte e do autor como produtor na contemporaneidade.

\section{Referências}

ADORNO, T. Engagement. In: ADORNO, T. Notas de literatura. Tradução de Celeste Aída Galeão e Idalina Azevedo da Silva. Rio de Janeiro: Tempo Brasileiro, 1991. p. 51-71.

ARENDT, H. Bertolt Brecht (1898 - 1956). In: ARENDT, H. Homens em tempos sombrios. Tradução de Denise Bottmann. São Paulo: Companhia das Letras, 2008. p. 151-184.

BENJAMIN, W. Ensaios sobre Brecht. Tradução de Claudia Abeling, São Paulo: Boitempo, 2017.

BENJAMIN, W. O Narrador: considerações sobre a obra de Nikolai Leskov. In: BENJAMIN, W. Magia e técnica, arte e política: ensaios sobre literatura e história da cultura. Tradução de Sergio Paulo Rouanet. São Paulo: Brasiliense, 1994. p. 197-221.

BENJAMIN, W. Sobre o conceito da História. In: BENJAMIN, W. Magia e técnica, arte e política: ensaios sobre literatura e história da cultura. Tradução de Sergio Paulo Rouanet. São Paulo: Brasiliense, 1994. p. 222-232.

BOLLE, W. A linguagem gestual no teatro de Brecht. Língua e Literatura, v. 5, p. 393-410, 1976.

BRECHT, B. Acerca da música-gesto. In: BRECHT, B. Estudos sobre teatro. Tradução de Fiama Pais Brandão. Rio de Janeiro: Nova Fronteira, 1978. p. 193-197.

BRECHT, B. Bertolt Brecht: teatro completo, volume 12. In: BRECHT, B. Decadência do egoísta Johann Fatzer. Tradução de Ingrid D. Koudela. São Paulo: Paz e Terra, 1995. p. 205-223.

BRECHT, B. Histórias do sr. Keuner. Tradução de Paulo César de Souza. São Paulo: Editora 34, 2013.

BRECHT, B. Poemas 1913 - 1956. Tradução de Paulo César de Souza. São Paulo: Editora 34, 2000. 
DIDI-HUBERMAN, G. Quando as imagens tomam posição. Tradução de Cleonice Paes. Belo Horizonte: Editora UFMG, 2017.

MELO, V. B. C. "A verdade, minha casa e meu carro!". In: BRECHT, B. Histórias do sr. Keuner. Tradução de Paulo César de Souza. São Paulo: Editora 34, 2013. p. 125-135.

Recebido em: 29 de julho de 2020 Aceito em: 13 de outubro de 2020 Publicado em dezembro de 2020 